\title{
Breast carcinoma cellularity and its relation to oestrogen receptor content
}

\author{
D M PARHAM, P R BAKER, $\dagger$ A J ROBERTSON, A VASISHTA, * P G BAKER, * \\ G SMITH*
}

From the Departments of Pathology and *Surgery, Ninewells Hospital and Medical School, Dundee, Scotland, and the †University Department of Surgery, Queen Elizabeth Hospital, Birmingham

SUMMARY The cellularity of 104 primary breast carcinomata was determined by semiautomated image analysis to allow the relation between cellularity and oestrogen receptor content values to be assessed. The oestrogen receptor content of tumours detected by a steroid binding assay showed no correlation with cellularity, although a possible weak negative correlation was observed between tumour cellularity and oestrogen receptor content detected by enzyme immunoassay. It is concluded that there is no single direct correlation between tumour cellularity and oestrogen receptor content.

It is widely accepted that assessment of the presence of oestrogen receptors (ER) in breast carcinomata is of value in predicting prognosis and the response to hormone therapy. ${ }^{1}$ The most widely used method determines receptor content on tissue homogenates. The results, therefore, do not directly take into account what proportion of the homogenised tissue comprises malignant cells rather than collagenous stroma or inflammatory cells, and the cellularity of individual breast carcinomas may vary 10 -fold or more. ${ }^{23}$ Several studies have tried to show the effect of tumour cellularity of ER content but the methods used assessed cellularity subjectively and produced contradictory findings. ${ }^{411}$ In this study we assessed cellularity objectively using semiautomated image analysis. The study was designed to allow the relation between cellularity and ER values to be assessed at two different times in an attempt to evaluate any influence of changes in ER assay "performance" and to determine if any difference in cellularity occurred. The data also allowed the two methods of quantitation of ER and their relation to cellularity to be compared.

\section{Material and methods}

Patients with a histological diagnosis of primary infiltrating breast carcinoma, in whom tumour ER assays had been performed and for which satisfactory tissue blocks were still available, were selected retrospectively from the Ninewells Breast Survey database. Sufficient histological material was needed so that the cellularity of a tissue section, which was subjectively

Accepted for publication 25 May 1989 representative of the tumour as a whole, could be assessed. Fifty consecutive cases which satisfied these criteria were selected from 1983 and 54 from 1986. The latter group had ER data determined by both assay methods (see below). Patients ranged from 28 to $8 A$ years of age (median 58 years): 32 were premenopausa and 74 postmenopausal at diagnosis.

\section{MICROSCOPIC EXAMINATION}

The cellularity of a neoplasm was assessed by image analysis, which was used to determine the proportion of a section of tumour occupied by malignant cells. The method, using the Quantimet 970, has been described in detail elsewhere. ${ }^{12}$ Sections stained with haematoxylin and eosin considered to be representative of the tumour were used. Due to the nonuniform distribution of malignant cells in a neoplasm consecutive non-overlapping fields (total magnification $\times 100$ ) across a section from periphery to centre and back were assessed. This was repeated until a total of 20 fields had been analysed. The average result was calculated and expressed as a percentage of the neoplasm (malignant cells plus stroma) occupied by malignant cells.

OESTROGEN RECEPTORS

The storage of tumour tissue, homogenisation and preparation of cytosol, and determination of oestrogen receptor content by radioligand steroid binding assay (ER-SBA) were as previously described for this laboratory. ${ }^{13}$ A Scatchard plot which did not yield a significant linear correlation was considered to indicate that the tumour had no receptor content. ${ }^{13}$ In 1986 ER was also quantitated in the same cytosol .

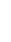


Table Correlation coefficients (Kendall's $\tau$ ) for cellularity and ER (fmol/mg protein)

\begin{tabular}{lllllll}
\hline Groups compared & & & $(n=)$ & $\tau$ & $z$ & $p$ value \\
\hline Cellularity & ER-SBA & $(1983)$ & 50 & -0.138 & -1.412 & $>0.16$ \\
Cellularity & ER-SBA & $(1986)$ & 54 & -0.156 & -1.66 & $>0.1$ \\
Cellularity & ER-EIA & $(1986)$ & 54 & -0.237 & -2.53 & $<0.02$ \\
Cellularity & ER-SBA & $(1983+86)$ & 104 & -0.136 & -2.05 & $<0.05$ \\
*ER-SBA & ER-EIA & $(1986)$ & 54 & -0.568 & 6.06 & $<0.00001$ \\
\hline
\end{tabular}

*Pearson product-moment correlation coefficient, $r=0.784$, ER-EIA $=1.05$, ER-SBA - 15.69.

preparations by an enzyme immunoassay (ER-EIA; trogen receptor content by radioligand steroid binding assay (ER-SBA) were as previously described for this laboratory. ${ }^{13}$ A Scatchard plot which did not yield a significant linear correlation was considered to indicate that the tumour had no receptor content. ${ }^{13}$ In 1986 ER was also quantitated in the same cytosol preparations by an enzyme immunoassay (ER-EIA; Abbott Laboratories) according to the assay procedure provided with the EIA kits. The results obtained were expressed as fmol oestrogen receptor/ $\mathrm{mg}$ cytosol protein. The steroid receptor laboratory was an active member of the UK Steroid Receptor Quality Assessment Group during the period of this study and routinely assayed EORTC quality control material.

The significance of any correlation between cellularity and ER content was tested by determining the correlation coefficient using a non-parametric ranking (Kendall's $\tau$ method). As multiple correlations were being performed a result was considered to be significant at a probability of 0.01 or less. Comparison of cellularity and ER-SBA between 1983 and 1986 was carried out by the non-parametric Mann Whitney

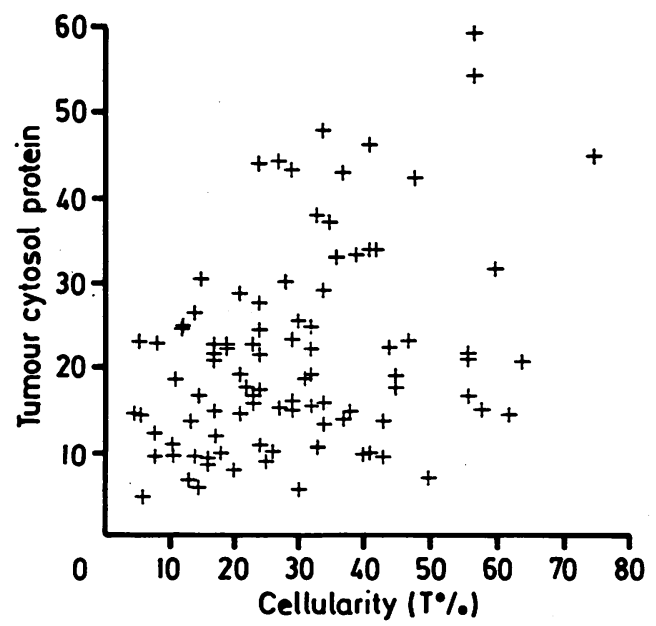

Figure Relation between tumour cytosol protein ( $\mathrm{mg} / \mathrm{g}$ tissue wet weight) and cellularity.
$\mathrm{U}$ test, for which a p value of $\leqslant 0.05$ was considered to be significant.

\section{Results}

As expected, no difference in the range of cellularity was observed in the carcinomas diagnosed in 1983 and $1986(1983$ median $=25 \%, 1986$ median $=29 \%, p>$ $0.7)$ or for ER content $(1983$ median $=16 \mathrm{fmol} / \mathrm{mg}$ cytosol protein, 1986 median $=0 \mathrm{fmol} / \mathrm{mg}$ cytosol protein $\mathrm{p}>0 \cdot 3$ ). Equally, no significant difference was observed in the ER content (ER positive $\geqslant 20$ $\mathrm{fmol} / \mathrm{mg}$ ) obtained with the SBA method in the two years examined (1983 ER positive $=23$, ER negative $=27 ; 1986 \mathrm{ER}$ positive $=22$, ER negative $=32)\left(\chi^{2}\right.$ test $=0.28,1 \mathrm{df}, 0.75>\mathrm{p}>0.5$ ).

A good correlation was observed between the ER content in breast tumours detected by the different methods of analysis. Surprisingly, the non-parametric analyses suggest an inverse correlation between cellularity and ER content, although only for the enzyme immunoassay did the results approach significance. A summary of the findings is presented in the table. The menopausal status of the women did not affect the findings.

The figure shows the correlation between tumour cytosol protein expressed as $\mathrm{mg} / \mathrm{g}$ tissue wet weight (data available for 96 cases) and cellularity. Analysis of the data with ER expressed as $\mathrm{fmol} / \mathrm{mg}$ wet weight of tissue resulted in similar findings to those in the table.

\section{Discussion}

No significant difference was observed in the cellularity or ER content between the two groups of tumours taken from 1983 and 1986. A good correlation was also shown to exist between the ER results obtained by the two assay methods used.

The detection of ER content in breast cancer by biochemical methods relies on the use of tissue homogenates and ER content has traditionally been expressed as fmol/mg tissue cytosol protein. Previous workers have found no correlation between ER-SBA content expressed as $\mathrm{fmol} / \mathrm{mg}$ tumour cytosol protein or $\mathrm{fmol} / \mathrm{mg}$ weight wet and tumour cellularity when 
assessed subjectively. ${ }^{46910}$ Other authors, however, have claimed that cellularity still influences ER-SBA content but only for ER positive tumours, ${ }^{711}$ and Mumford, using an objective point counting technique, found a significant positive correlation between cellularity and all ER values, but only for postmenopausal women. ${ }^{8}$

In contrast to the findings made by these workers, we observed a possible, albeit weak, negative correlation between cellularity and ER detected by the newer enzyme immunoassay. This assumes that the tissue submitted for biochemical analysis was of a similar cellularity to that used to assess cellularity. In a propective study it may be possible to obtain a better correlation if contiguous samples are taken. The negative correlation between measurement of cellularity and ER-EIA raises the interesting question as to the possibility that the stroma may be producing a local paracrine effect which stimulates the malignant epithelial cells to produce oestrogen receptor.

The lack of a significant correlation between ER content and cellularity could be attributed to the method of expressing oestrogen receptors $(\mathrm{fmol} / \mathrm{mg}$ tumour cytosol protein). In this paper we have shown that there may be a seven- to 10-fold difference in tumour cytosol protein concentration at any given cellularity. In an attempt to establish if there is a more direct correlation between cellularity and oestrogen receptor content, oestrogen receptors were expressed as a function of wet weight (fmol/mg wet weight homogenised tissue). The results did not change the findings. Presumably, ER content is a function of both cellularity and the amount of receptor expressed by individual malignant cells, and both parameters may vary from tumour to tumour. Another variablenamely, a stromal paracrine effect-could also influence the amount of ER harvested from tissue homogenates.

Individual tumour cell oestrogen receptor content may also be important in determining overall ER content in breast carcinomata, and there is evidence, albeit from tissue homogenates, to suggest that the relative amount of ER in tumour cells may be of prognostic value.$^{14} 15$ It is therefore important that a technique is developed which can determine the ER content of a tumour by taking into account both the cellularity and receptor content in individual cells, particularly as a positive correlation has been shown to exist between tumour cellularity and survival. ${ }^{3}$ An assessment of ER, which takes into account both of these factors, may produce a more meaningful result of greater prognostic value. Image analysis using the Quantimet 970 has recently been shown to be accurate in quantifying differentiation products detected by monoclonal antibodies in breast carcinomata and the results can be expressed as a function of tumour cellularity. ${ }^{12}$ By using this method, the true relation between oestrogen receptors and cellularity may be determined. A monoclonal antibody directed against oestrogen receptors, which can be reliably used in paraffin wax sections, would be of considerable benefit.

We thank Professor JS Beck for his encouragement and support in this work.

\section{Referemces}

1 Walt AJ, Singhakowinta A, Brooks SC, Cortez A. The surgical implications of estrophile protein estimations in carcinoma of the breast. Surgery 1976;00:506-12.

2 Underwood JCE. Morphometric analysis of human breast carcinoma. Br J Cancer 1972;26:234-7.

3 Parham DM, Brown RA, Robertson AJ. Morphometric analysis of breast carcinoma: relationship to survival. J Clin Pathol 1988;41:173-7.

4 Wittliff JL, Hilf R, Brooks WF, et al. Specific estrogen binding capacity of the cytoplasmic receptor in normal and neoplastic breast tissues of humans. Cancer Res 1972;32:1983-92.

5 Rosen PP, Menendez-Botet CJ, Nisselbaum JS, et al. Pathological review of breast lesions analyzed for estrogen receptor protein. Cancer Res 1975;35:3187-94.

6 Di Fronzo G, Clemente C, Capelletti V, et al. Relationship between ER-ICA and Conventional steroid receptor assays ik human breast cancer. Breast Cancer Res Treat 1986;8:35-43.

7 Mason RE, Steel RJC, Hawkins RA, Miller WR, Forrest APM? Cellularity and the quantitation of estrogen receptors. Breast Cancer Treat Res 1982;2:239-42.

8 Mumford CJ, Elston CW, Campbell FC, et al. Tumour epithelial cellularity and quantitative oestrogen receptor values in primary breast cancer. Br J Cancer 1983;47:549-52.

9 Feherty P, Farrer-Brown G, Kellie AE. Oestradiol receptors in carcinoma and benign disease of the breast: an in vitro assay. Br J Cancer 1971;25:697-710.

10 Terenius L, Johansson H, Rimsten A, Thoren L. Malignant and benign human mammary disease: estrogen binding in relation to clinical data. Cancer 1974;33:1364-8.

11 Masters JRW, Hawkins RA, Sangster K, et al. Oestrogen receptors, cellularity elastosis and menstrual status in human breast cancer. Eur J Cancer 1978;14:303-7.

12 Parham DM, Slidders W, Robertson AJ. Quantitation of human milk fat globule (HMFG1) expression in breast carcinoma and its association with survival. J Clin Pathol 1988;41:875-9.

13 Vashishta A, Baker PR, Preece PE, Wood RAB, Cuschieri A. Protinase-like peptidase activities and oestrogen receptor levels in breast cancer tissue. J Cancer Res Clin Oncol 1989;115:89-92.

14 Jensen EV. Estrogen receptors in hormone dependent breast cancers. Cancer Res 1975;35:3362-4.

15 Leclercq G, Heuson JC. Therapeutic significance of sex-steroid hormone receptors in the treatment of breast cancer. Eur $J$ Cancer 1977;13:1205-15.

Requests for reprints to: Dr D M Parham, Department of Pathology, Ninewells Hospital and Medical School, Dundee, Scotland DD1 9SY. 
by pathologists for pathologists", and volume 1 compares favourably with the Recent Advances in Pathology series. The articles cover aspects of gynaecological, urological, and nephrological pathology.

Much of this volume describes cancers with low malignant potential, and the term "borderline" in ovarian tumours is used not only for serous and mucinous tumours, but also endometrioid, clear cell, Brenner and mixed Mullerian tumours. The diagnosis of persistent and proliferative gestational trophoblastic disease is clearly described.

There are chapters on early prostatic malignancy, and the lack of editorial censorship is shown by one author warning of the risks of treating incidental prostatic carcinoma, while the subsequent chapter advocates radical prostatectomy for similar lesions. The book also describes papillary prostatic urethral lesions and malignant testicular stroma tumours, and there are chapters on the multiple causes of crescentic glomerulonephritis and fibrillary glomerulonephritis.

This is a very valuable collection of articles, and reasonably priced. If subsequen volumes are of a similar standard Progress in Reproductive and Urinary Tract Pathology will be a very welcome series of publications. KM GRIGOR

Cyclosporin. Mode of Action and Clinical Application. Ed AW Thomson. (Pp 372; £50.) Kluwer Academic Publishers. 1990. ISBN 0 7462-0124-9.

It is trite to note that the use of cyclosporin has greatly enlarged the clinical possibilities of transplantation, and it is a truism to state that trying to understand the mechanism of its actions has pained immunologists by showing up a huge area of their ignorance. The understanding of molecular and cellular signal transduction and effector activation are being applied to cyclosporin and its new rival FK506, but there is still much to learn-and much to be learnt from studies of the pharmacology of cyclosporin.

Dr Thomson, whose own work has combined functional and morphological investigations in this field, has edited an attractive and useful synoptic account of our general understanding up to early 1989 . There are 15 chapters by active scientists and clinicians from Australia, Britain, France, Switzerland and the USA. They review in varying detail the effects of cyclosporin A on mechanisms of cellullar and humoral immune response initiation and amplification $(20 \%$ of the book), and its therapeutic potential or proven value in human diseases of the bone marrow, eye, diabetes, skin and autoimmune disorders $(40 \%)$. The remaining third covers pharmacokinetics, drug metabolism-harmful effects in clinical practice and pathological changes in experimental models.

Each chapter contains a tidy statement of current knowledge, plentiful illustrations, and a good supply of references. Most can only report phenomena, as our understanding is deficient, but others do discuss likely mechanisms involving binding to a specific cytoplasmic protein and downstream consequences on interleukin 2-mediated cell activation and proliferation.

To the basic scientist the book offers a useful but inevitably slightly dated review. For the applied researcher and clinician it provides valuable guidance on the possibilities and problems of treatment. For a compound with such a narrow therapeutic range it is disappointing that almost no author describes the detail of any dosing regimen used-the drug is just administered! Apart from that lapse, $\mathrm{Dr}$ Thomson has provided a book of great use to immunologists and pathologists.

AD DAYAN

Management of Orbital and Ocular Adnexal Tumours and Inflammations. Ed JA Mauriello, JC Flanagan. (Pp 285; Hardcover DM 280.00.) Springer. 1990 ISBN 3540511555 .

This is a profoundly disappointing book which is a great pity because it contains some very good things. These include excellent photomicrographs, clinical illustrations, and gross pathological photographs, many of rare entities, culled from AFIP alumni and from Dr Flanagan's extensive practice. There are also a large number of well organised table throughout the book. These good points only serve to highlight the deficiencies and chao of the text. Although designed to be dipped into, rather than read as a whole, the organisation of the text constantly flits from one topic to another and frequently places a whole team of horses before the cart. I asked two "busy ophthalmologists", at whom the book is aimed, to look at it; both found the format and indexing irritating and elusive. From the pathologist's standpoint it is unsatisfactory to have paragraph headings of conditions that are not synonymous and to describe only the first, an example being: angiolymphoid hyperplasia (Kimura's disease, eosinophilic granuloma, eosinophilic folliculosis) when only Kimura's disease is described. Pick ou the plums and you will enjoy it. Read it all and you risk indigestion.

ACE MCCARTNEY

Pharmacology-Drug Actions and Reactions. Ruth R Levine. (Pp 576; sof cover £24.95) Churchill Livingstone. 1990. ISBN 0-316-52217-1

This book is a useful introduction to the concepts of pharmacology and toxicology. Many medical graduates will have covered most of the ideas presented in their undergraduate years. The clinical scientist or MLSO rotating through his or her department's drug analysis section for the first time, however, will find it invaluable. Indeed, the hardest part of writing this review has been prising the book loose from the toxicology section, where it has rapidly become a fixture on the bookshelf alongside Clark, Goodman, and Gilman, the British National Formularly, and the Data Sheet Compendium. Strongly recommended: a definite "best buy". ARW FORREST

\section{NOTICES}

\section{ACP Locum Bureau}

The Association of Clinical Pathologists runs a locum bureau for consultant pathologists.

Applicants with the MRCPath who would like to do locums and anyone requiring a locum should contact The General Secretary, School of Biological Sciences, Falmer, Brighton, BN1 9QC Tel and Fax: 0273678435.

\section{Lung Pathology}

London, 10-12 June 1991

A comprehensive course of lectures, hands-on microscopy sessions, and a slide seminar will be held at the Brompton Hospital. The programme will include J Wigglesworth on perinatal disease, $M$ Dunnill on defence mechanisms and fibrosis, A Gibbs on pneumoconiosis, $\mathrm{C}$ Wagenvoort on hypertension and a variety of internal speakers on airway disease, infections, interstitial disease, angiitis and tumours.

Fee $£ 150$ (or US\$290).

Applications to Professor B Corrin, Histopathology, Brompton Hospital, London SW3 6NP.

\section{Centre for Health Planning and Management \\ Diploma in Management (Diagnostic Services)}

Applications are invited for places on this part-time diploma, beginning in October 1991. It is aimed at heads of department and potential heads in Pathology.

The Diploma in Management covers applied management principles, health policy, management of human resources and operations management. It aims to provide the candidate with a sound backing in both scientific and behaviourial aspects of management, and the curriculum relates to the NHS of the 1990s and beyond. Potential applicants wishing to discuss the programme further should contact either Professor Roger Dyson or Dr Calum Paton on 0782 621111 (ext 3646).

Further details and full application materials are available from: Tanya Matthews, Centre for Health Planning and Management, Suite 2.1, Science Park, University of Keele, Staffordshire, ST5 5SP

\section{Corrections}

An error appeared in the bottom line of the first column of the table in the letter, "Are calculated globulin measurements useful in screening for paraproteinaemia?" ( $J$ Clin Pathol 1990;43:694). The correct line should have read:

Specificity $=\mathrm{TN} / \mathrm{FP}+\mathrm{TN} \times 100=$ $96 \cdot 7 \%$.

Two authors names were omitted from a letter to the Editor, "Breast carcinoma cellularity and its relation to oestrogen receptor content." (J Clin Pathol 1989;42:1166-8). The names of P Coy of the Victoria Cancer Clinic, The Cancer Control Agency of British Columbia, and $C$ Fletcher of the Special Development Laboratory, Greater Victoria Hospital Society, should have been included. 